\title{
Discussão sobre a inserção de tópicos de relatividade no ensino médio: análise na voz de professores de Física em formação
}

Discussion on the insertion of relativity topics in high school: voice analysis of physics teachers in training

\author{
Alisson Cristian Giacomelli ${ }^{1}$ \\ Carlos Ariel Samudio Perez ${ }^{2}$ \\ Cleci T. Werner da Rosa ${ }^{3}$
}

\section{Resumo}

O presente estudo relata o desenvolvimento, aplicação e avaliação de uma proposta didática para contemplar tópicos da Teoria da Relatividade Restrita e da Teoria da Relatividade Geral no ensino médio. O estudo foi desenvolvido junto a um grupo de estudantes universitários futuros professores de Física, no interior do Rio Grande do Sul. A problemática abordada parte da necessidade de inserir tais conteúdos no ensino médio e toma como questionamento principal a viabilidade de abordar esses tópicos na organização sugerida, envolvendo situações de aprendizagem condizentes com esse nível de escolarização. Mas especificamente, o objetivo é investigar as contribuições dessa proposta didática como favorecedora da aprendizagem e capaz de estimular os acadêmicos a adotá-la no exercício profissional futuro. Para tanto, utilizou-se uma investigação qualitativa como referencial metodológico, embora também tenha-se usado dados numéricos, mas que foram analisados à luz da interpretação do fenômeno em discussão. Como instrumentos de coleta de dados, o estudo recorre à aplicação de questionários (pré e pós-teste), completando com registros do professor-pesquisador em seu diário de bordo. Os resultados indicam uma significativa evolução nos conhecimentos dos estudantes o que remete a potencialidade da atividade desenvolvida em termos de indícios de aprendizagem.

Palavras-chave: Física Moderna, Relatividade, Ensino Médio.

\section{Abstract}

The present study reports the development, application and evaluation of a didactic proposal to contemplate topics of the Theory of Restricted Relativity and the Theory of General Relativity in high school. The study was developed with a group of university students - future Physics teachers, in the inland Rio Grande do Sul. The approached problematic comes from the need to include these subjects in high school and takes into question the viability of approaching these topics in the suggested organization, involving learning situations consistent with this level of schooling. But specifically, the goal is to investigate the contributions of this didactic proposal as favoring learning and able to encourage academics to adopt it in future professional practice. Therefore, a qualitative investigation was used as a methodological

\footnotetext{
${ }^{1}$ Universidade de Passo Fundo | alissongiacomelli@upf.br

2 Universidade de Passo Fundo | samudio@upf.br

3 Universidade de Passo Fundo | cwerner@upf.br
} 
reference, although numerical data were also used, but were analyzed in light of the interpretation of the phenomenon under discussion. As data collection instruments, the study uses the application of questionnaires (pre and post test), complete with records of the teacher-researcher in his logbook. The results indicate a significant evolution in the students' knowledge, which refers to the potentiality of the activity developed in terms of learning signs. Keywords: Modern Physics, Relativity, High School.

\section{Introdução}

A evolução do conhecimento científico conduz a uma visão cada vez mais ampla e crítica do mundo. Essa visão precisa permear o pensamento dos professores do ensino médio, e estes, por sua vez, devem levá-la para a sala de aula. No que diz respeito à Física, um salto importante e abrupto na evolução do conhecimento científico ocorreu com o surgimento da chamada Física Moderna (FM). A mudança na forma de interpretar o mundo decorrente dessa nova Física não tem qualquer paralelo na história. As novas teorias são contra intuitivas, abstratas, extremamente imaginativas e conduzem a uma interpretação dos fenômenos naturais que difere significativamente das que se haviam construído até então. Compreender e aceitar as consequências dessa nova visão de mundo pode se mostrar complexa para um físico experiente e se revela um verdadeiro desafio para os estudantes do ensino médio. No entanto, esse desafio intelectual pode se tornar um importante elemento no processo de ensino e aprendizagem em Física, servindo de referência para discussões mais profundas e que ultrapassam os limites desta ciência. Nesse contexto, defendemos a importância da inserção da FM no ensino médio, como forma de introduzir um novo modo de pensar, além de aproximar os estudantes de eventos presentes no seu entorno.

Nos Estados Unidos, as discussões sobre a inserção dos conteúdos relacionados a FM no ensino médio, se intensificaram a partir da "Conferência sobre o Ensino de Física Moderna", realizada no Fermi National Accelerator Laboratory, Batavia, Illinois, em abril de 1986. Nessa conferência, cerca de cem professores interagiram com aproximadamente quinze físicos. $O$ principal objetivo das discussões estava em promover a abordagem de tópicos de FM em escolas de nível médio, assim como em cursos introdutórios de graduação. No Brasil, esse movimento se intensificou a partir da publicação dos Parâmetros Curriculares Nacionais (PCNs) no final dos anos de 1990, que reforçou a necessidade da formação de um cidadão atualizado e crítico que interage com o mundo a sua volta.

Para que ocorra essa interação crítica, o cidadão precisa ter ao menos um conhecimento básico sobre as leis da natureza. Somente assim ele poderá compreender, por exemplo, as implicações de um tratamento de radioterapia, o funcionamento de sensores fotoelétricos, aparelhos de GPS (do inglês Global Positioning System) e de muitas outras tecnologias presentes em seu cotidiano, bem como compreender notícias sobre novas pesquisas e teorias que constantemente são veiculadas nos mais variados meios de comunicação. No caso da Teoria da Relatividade Restrita (TRR), considerada um dos pilares da FM, a compreensão de algumas das suas implicações pode ser uma forma de despertar o interesse pela Física e de estabelecer no sistema cognitivo do estudante uma nova forma de interagir com o mundo a sua volta. A necessidade de observar o mundo de uma forma diferenciada é uma das consequências do estudo desta teoria, bem como da Teoria da Relatividade Geral (TRG), objetos de discussão deste texto. 
Embora se justifique a importância da FM no ensino médio, trabalho como o desenvolvido por Terrazzan (1992), por exemplo, há mais de 20 anos, já destacava que o currículo das escolas de educação básica no Brasil segue, basicamente, a sequência adotada pelos modelos estrangeiros, que geralmente excluem a Física desenvolvida no século XX. Tal identificação permanece presente na realidade da escola, embora os livros didáticos tenham, a partir dos anos de 1990 incluídos tópicos relativos a esse campo de conhecimento. Todavia, Rezende (2001) mostra que a inserção de tópicos de FM no ensino médio ainda precisa superar alguns obstáculos, dentre os quais está a falta de preparo dos professores devido à deficiência da sua formação nos cursos de graduação em Física.

Tais constatações levaram a buscar alternativas para abordar tópicos da TRR e da TRG com licenciandos em Física, de modo a desenvolver uma proposta didática que possibilite favorecer o processo de construção dos conhecimentos e, ao mesmo tempo, possa servir de referência para subsidiar sua ação docente. Especificamente, o intuito é desenvolver e avaliar uma proposta didática elaborada a partir da necessidade de fomentar a discussão da TRR e da TRG na licenciatura em Física, envolvendo situações de ensino que possam ser utilizadas no ensino médio. Deste modo o presente estudo tem por objetivo investigar as contribuições de uma proposta didática para apropriação dos conteúdos. Neste recorte da investigação, analisamos como futuros professores de Física que ainda não tiveram contato com os tópicos anunciados, concebem as atividades didáticas desenvolvidas como favorecedoras da construção dos conteúdos.

As discussões teóricas para a elaboração da proposta tomam como referência a didática francesa, com a Transposição Didática (TD) em Yves Chevallard, acrescida das discussões de Jean-Pierre Astolfi. Em termos metodológicos, o estudo adota uma pesquisa de natureza qualitativa e vinculada à análise de um processo de intervenção didática. A coleta de dados utilizou um pré e pós-teste e o registro em um diário de bordo de um pesquisador que assumiu a condição de professor da turma e que é um dos autores deste artigo. Tais aspectos estão organizados no texto de modo a apresentar o referencial teórico e na sequência a proposta didática desenvolvida. A seguir, são descritos e analisados os resultados, para ao final tecer as considerações do estudo.

\section{Referencial teórico}

O presente estudo encontra-se apoiado na perspectiva teórica de Yves Chevallard com contribuições de Jean-Pierre Astolfi frente à especificidade da TD. Tal perspectiva possibilita analisar as características que são necessárias para a estruturação de um conhecimento na forma de material didático. O aspecto central da teoria da TD parte da identificação de que a forma como os conteúdos são abordados em sala de aula, no geral, diferencia-se da forma como eles se apresentam em sua formulação original pelos cientistas. Para Chevallard (1991), o saber (conhecimento) pode ser dividido em três esferas: saber sábio; saber a ensinar; saber ensinado. O saber sábio refere-se a aquele produzido originalmente pelo cientista, que é submetido a adequações a fim de compatibilizá-lo com as regras e normas específicas para divulga-lo na comunidade científica. O saber a ensinar apresenta as adaptações que o saber sábio sofre para se constituir como objeto de ensino, normalmente realizado para integrar os livros didáticos, manuais de ensino e programas escolares. No processo de TD entre o saber sábio e o saber a ensinar, o conhecimento passa por um processo de reestruturação que o leva a, de certa forma, desligar-se do contexto em que foi elaborado originalmente, 
assumindo uma nova estrutura, de caráter ordenado, com uma sequência lógica e um novo caráter epistemológico. Esse processo é chamado por Chevallard (1991) de "despersonalização", que consiste no saber perder o seu contexto original, assumindo novas características estruturais e epistemológicas. Os responsáveis neste processo de adaptação são os principais envolvidos no processo de ensino, como, por exemplo, os autores de livros didáticos, especialistas das disciplinas, professores, o poder público e demais ramos da sociedade envolvidos nos processos de ensino e aprendizagem. Por fim temos, o saber ensinado que representa as transformações que ocorrem no saber a ensinar que se encontra nos livros (e outros materiais) didáticos em algo que se julga adequado aos alunos. O principal ator neste processo de transformação é o professor, e deve realizá-lo levando em consideração a realidade da escola na qual está inserido. Também podem ser atores os alunos, a administração escolar e outros membros da comunidade mais próximos à escola. Após essas adequações, caracterizadas pelos saberes indicados por Chevallard (1991), é que o conhecimento de fato chega até o estudante. Ou seja, desde a sua formulação original, o conhecimento sofre reformulações, sendo responsáveis por isso todos os envolvidos no processo. A esse grupo de pessoas e setores da sociedade o autor dá o nome de "noosfera". Ela tem como principal função a otimização do ensino, visando uma forma mais eficiente de conduzir todo o processo inclusive no que diz respeito à seleção de quais tópicos serão levados para a sala de aula.

Em todo o processo de TD, desde o saber sábio até o saber a ensinar Chevallard (1991) aponta que, algumas características determinantes precisam ser observadas para a sobrevivência do conhecimento no nível do saber a ensinar. Para ele o saber a ensinar deve: (i) ser consensual, ou seja, não podem haver dúvidas sobre a "veracidade" daquilo que se está ensinando; (ii) ter atualidade moral o que está relacionada com à aceitação da sociedade em que se está ensinando um determinado saber; (iii) ter atualidade biológica o que está relacionada a àquilo que é aceito no meio científico de uma determinada época; (iv) ter operacionalidade o que diz respeito à possibilidade de se gerar exercícios, situações problema, tarefas e demais situações didáticas junto aos estudantes; (v) apresentar criatividade didática, ou seja, permitir que os envolvidos no processo de ensino e aprendizagem desenvolvam atividades direcionadas exclusivamente à sala de aula; e, (vi) ser terapêutico, ou seja, por ter se adaptado à realidade escolar de uma forma eficiente continua sendo trabalhado no âmbito escolar.

Quadro 1 - Regras associadas à Transposição Didática

\begin{tabular}{|c|c|}
\hline Regra & Descrição \\
\hline $\begin{array}{c}\text { Modernizar o saber } \\
\text { escolar }\end{array}$ & $\begin{array}{l}\text { Considera que a ciência está em constante avanço, o que impacta } \\
\text { diretamente na evolução da indústria e tecnologia, portanto, é } \\
\text { necessário que os saberes discutidos na escola estejam a par das novas } \\
\text { teorias científicas e dos avanços tecnológicos. Só desta forma a escola, } \\
\text { poderá cumprir uma das suas principais funções que é formar um } \\
\text { cidadão atualizado e informado acerca do desenvolvimento da } \\
\text { sociedade nas mais diversas áreas. }\end{array}$ \\
\hline $\begin{array}{c}\text { Atualizar o saber a } \\
\text { ensinar }\end{array}$ & $\begin{array}{l}\text { O saber a ensinar na escola deve ser frequentemente atualizado para } \\
\text { se manter mais próximo do saber sábio, levando a necessidade de } \\
\text { renovar os conceitos e impedir que os não mais aceitos pela } \\
\text { comunidade científica continuem estando presentes na escola. }\end{array}$ \\
\hline
\end{tabular}




\begin{tabular}{|c|c|}
\hline $\begin{array}{l}\text { Articular o saber } \\
\text { novo com o antigo }\end{array}$ & $\begin{array}{l}\text { A inserção de um novo saber deve ocorrer de forma articulada com o } \\
\text { saber já discutido tradicionalmente, cuja ausência pode gerar uma } \\
\text { visão de instabilidade daquele conhecimento. Isso pode favorecer a } \\
\text { visão de que ele sempre será substituído por outro que virá na } \\
\text { sequência. Por outro lado, essa articulação facilita a aprovação e a } \\
\text { permanência do saber novo. }\end{array}$ \\
\hline $\begin{array}{l}\text { Transformar um } \\
\text { saber em exercícios e } \\
\text { problemas }\end{array}$ & $\begin{array}{l}\text { O saber sábio deve oferecer possibilidades para gerar exercícios e } \\
\text { atividades didáticas. Essa regra é fundamental para à permanência de } \\
\text { um saber no âmbito escolar, uma vez que o professor faz uso dessas } \\
\text { ferramentas em seu fazer pedagógico, inclusive nos processos de } \\
\text { avaliação. }\end{array}$ \\
\hline $\begin{array}{l}\text { Tornar um conceito } \\
\text { mais compreensível }\end{array}$ & $\begin{array}{l}\text { O processo que leva o saber sábio até o saber a ensinar visa facilitar a } \\
\text { compreensão de conceitos, exigindo uma linguagem compreensível } \\
\text { ao estudante. }\end{array}$ \\
\hline
\end{tabular}

Fonte: os autores, 2018.

Astolfi (1995), baseando-se nas características definidas por Chevalard (1991) elaborou cinco regras a serem seguidas no processo de TD, as quais subsidiaram a elaboração da proposta didática em discussão neste estudo. Tais regras estão descritas no quadro 1.

As regras mencionadas subsidiaram a elaboração da proposta didática deste estudo, assim como tem subsidiados estudos envolvendo a operacionalização desta perspectiva teórica em outros contextos educacionais com é o caso do estudo desenvolvido por Gonçalves e Bittar (2017). Além disso, justificam o mesmo, uma vez que muitos tópicos da FM ainda se encontram em um processo de TD e, por consequência, não estão consolidados na escola.

\section{A proposta didática}

A proposta didática teve como foco abordar os conteúdos da TRR e da TRG em um curso de formação de professores de Física, levando em consideração a possibilidade de que essas atividades subsidiem ações no ensino médio. Tal proposta inclui textos didáticos, atividades experimentais, uso de tecnologias computacionais e resolução de exercícios, que por limitações textuais será relatada no quadro 2 sem detalhamentos. Esse, por sua vez, é explorado no momento em que são analisados os registros do pesquisador no seu diário de bordo.

Quadro 2 - Relação das atividades desenvolvidas na proposta didática.

\begin{tabular}{|c|c|c|}
\hline$E^{4}$ & Tema abordado & Atividades desenvolvidas \\
\hline $1^{0}$ & $\begin{array}{l}\text { A relatividade Clássica: Galileu } \\
\text { e Newton }\end{array}$ & $\begin{array}{l}\text { Apresentação da proposta e aplicação do pré-teste. } \\
\text { Experimentos de pensamento } \\
\text { Resolução de exercícios }\end{array}$ \\
\hline $2^{\circ}$ & $\begin{array}{l}\text { Os postulados de Einstein para } \\
\text { a TRR. } \\
\text { Relatividade da simultaneidade } \\
\text { Dilatação temporal. }\end{array}$ & $\begin{array}{l}\text { Leitura de textos de apoio. } \\
\text { Experimentos de pensamento e em laboratório } \\
\text { didático. } \\
\text { Formalização das relaç̃̃es matemáticas. } \\
\text { Resolução de exercícios. }\end{array}$ \\
\hline $3^{\circ}$ & Contração das distâncias & Experimento em laboratório didático. \\
\hline
\end{tabular}

\footnotetext{
${ }^{4}$ A coluna corresponde a ordem dos encontros, cuja duração foi de quatro períodos de 45 minutos cada um.
} 


\begin{tabular}{|c|c|c|}
\hline & & $\begin{array}{l}\text { Formalização das relações matemáticas. } \\
\text { Resolução de exercícios. }\end{array}$ \\
\hline $\begin{array}{l}4 \\
\circ\end{array}$ & $\begin{array}{l}\text { TRG - introdução } \\
\text { Princípio de equivalência } \\
\text { A TRG e a relatividade do } \\
\text { tempo }\end{array}$ & $\begin{array}{l}\text { Experimentos de pensamento. } \\
\text { Formalização das relações matemáticas para o } \\
\text { princípio da equivalência e para a relatividade do } \\
\text { tempo no âmbito da TRG. } \\
\text { Debate - tema: viagens no tempo. } \\
\text { Resolução de exercícios. }\end{array}$ \\
\hline $5^{\circ}$ & $\begin{array}{l}\text { Espaço curvo } \\
\text { Deflexão da luz }\end{array}$ & $\begin{array}{l}\text { Experimento de pensamento e em laboratório } \\
\text { didático. } \\
\text { Formalização das relações matemáticas para espaço } \\
\text { curvo e para a deflexão da luz. } \\
\text { Resolução de exercícios. } \\
\text { Aplicação do pós-teste }\end{array}$ \\
\hline
\end{tabular}

Fonte: Dados do estudo, 2016.

O quadro descreve os tópicos contemplados e as atividades correspondentes a cada encontro. Tais atividades seguem o proposto por Giacomelli (2016) e Giacomelli e Perez (2016) e foram estruturadas de modo a envolver a participação e o diálogo entre os acadêmicos. Além disso, a estruturação das atividades tomou como referências às discussões construtivistas, especialmente as propostas por ROSA (2011) de modo a envolver a problematização e o questionamento como linha norteadora das ações didáticas.

\section{Aspectos metodológicos da pesquisa}

No presente estudo adotamos uma investigação de natureza qualitativa e vinculada à análise de um processo de intervenção didática. A abordagem qualitativa, conforme Triviños (1994), busca compreender e analisar a realidade, possibilitando ao mesmo tempo compreender as atividades de investigação que podem ser específicas do estudo e identificar os traços comuns presentes nos dados e que podem responder às indagações da pesquisa. Tal opção tem sido adotada pela maioria das investigações em educação, que podem ou não se servir dos dados quantitativos como forma de subsidiar as discussões de natureza qualitativa. Esse foi o caso do presente estudo, que buscou, por meio dos seus instrumentos de coleta de dados, mesclar o quantitativo com o qualitativo, de modo a fornecer uma discussão sobre a pertinência da proposta didática em análise.

Para a coleta de dados, a pesquisa recorreu a dois instrumentos: questionários na forma de pré e pós-teste e diário de bordo. Os questionários de pré e pós-teste foram aplicados nos momentos anterior (pré-teste) e posterior (pós-teste) as atividades. Tais questionários destinam-se a verificar conhecimentos específicos vinculados à TRR e à TRG. No pré-teste foi incluído um conjunto de cinco perguntas relacionadas a sentimentos em relação ao estudo da TRR e da TRG. O conjunto de perguntas pretende verificar: se os tópicos mencionados despertam interesse e curiosidade; se é importante estudar tais conteúdos no processo de formação; e, qual a relevância desses tópicos no ensino médio.

O diário de bordo foi utilizado na perspectiva de Zabalza (2004), sendo entendido como espaço designado a registros, anotações e reflexões individuais sobre um determinado processo de aprendizagem. De acordo com o autor: "Os diários contribuem de uma maneira notável para o estabelecimento dessa espécie de círculo de melhoria capaz de nos introduzir 
em uma dinâmica de revisão e enriquecimento de nossa atividade como professores" (p. 12). No diário, foi possível proceder a anotações relacionadas às experiências vivenciadas e observadas no contexto da sala de aula durante a aplicação da proposta didática, registrando as ações desenvolvidas e a movimentação dos estudantes. Tais registros ocorreram sempre ao final das aulas e foram realizados de forma livre, mantendo-se como espinha dorsal do registro as ações e as observações do pesquisador/professor.

Os sujeitos que participaram do estudo, foram 17 acadêmicos de um curso de licenciatura em Física de uma universidade comunitária localizada no interior do Rio Grande do Sul, sendo nove do sexo masculino e oito do feminino. No texto esses acadêmicos serão identificados pelo gênero masculino.

\section{Análise dos dados coletados}

A análise dos dados está estruturada seguindo os instrumentos utilizados, sendo que inicialmente apresentamos e discutimos os resultados decorrentes da aplicação dos questionamentos e, na sequência, os registros do pesquisador em seu diário de bordo.

\section{Questionários}

Os questionários aplicados no início e no final da aplicação da proposta se diferenciavam em alguns itens, de forma que as primeiras cinco questões constavam apenas no pré-teste e, portanto, foram analisadas separadamente. A partir da sexta questão, os temas investigados estiveram presentes no pré e no pós-teste e são analisados de forma a confrontar as respostas. Os resultados obtidos são apresentados em tabelas, seguidos de sua análise.

Questão 1: Qual o seu nível de conhecimento sobre conceitos referentes à: TRR / TRG.

Tabela 1 - Respostas obtidas para a questão 1 do pré-teste

\begin{tabular}{|c|c|c|}
\hline Alternativas & TRR (\%) & TRG (\%) \\
\hline Nenhum & 46,7 & 53,2 \\
\hline Baixo & 53,2 & 46,7 \\
\hline Médio & 0,0 & 0,0 \\
\hline Alto & 0,0 & 0,0 \\
\hline
\end{tabular}

Fonte: dados de pesquisa.

Na tabela 1 podemos perceber que os licenciandos julgam que seu conhecimento sobre TRR e TRG se encontra entre "baixo" e "nenhum". Notamos que o valor atribuído a "baixo" em relação à TRR $(53,2 \%)$ migra para "nenhum" no que diz respeito à TRG, ilustrando uma inversão nas respostas. Sobre isso, temos que, durante a aplicação do questionário, a maioria dos estudantes expressou oralmente não saber qual é a diferença entre a TRR e a TRG.

Questão 2: Durante a sua educação básica (ensinos fundamental e médio) em algum momento foram discutidos tópicos referentes à: TRR / TRG.

Tabela 2 - Respostas obtidas para a questão 2 do pré-teste

\begin{tabular}{|c|c|c|}
\hline Alternativas & TRR (\%) & TRG (\%) \\
\hline Sim & 33,2 & 6,7 \\
\hline Não & 66,7 & 93,2 \\
\hline
\end{tabular}

Fonte: dados de pesquisa. 
De acordo com os dados dispostos na tabela 2, verificamos que a afirmação do grupo remete ao fato de que ainda é grande a carência no que diz respeito à abordagem da TRR na educação básica, mas que ela é ainda maior no que diz respeito à TRG (essa consideração é feita apenas para esse grupo particularmente).

Questão 3: Qual é o seu nível de interesse em estudar/aprender sobre conceitos referentes à: TRR / TRG.

Tabela 3 - Respostas obtidas para a questão 3 do pré-teste

\begin{tabular}{|c|c|c|}
\hline Alternativas & TRR (\%) & TRG (\%) \\
\hline Nenhum & ---- & ---- \\
\hline Baixo & ---- & ---- \\
\hline Médio & 13,2 & 13,2 \\
\hline Alto & 86,7 & 86,7 \\
\hline
\end{tabular}

Fonte: dados de pesquisa.

A tabela 3 aponta que, aproximadamente, 86,7\% dos licenciandos afirmaram ter alto nível de interesse em estudar/aprender sobre TRR e TRG. Esse resultado, confrontado com o resultado das questões anteriores, remete a uma necessidade de se aperfeiçoar o ensino da teoria da relatividade no ensino médio. Isso porque a maioria dos estudantes respondeu ter um nível muito baixo de conhecimento em TRR e TRG, assim como mencionou não ter estudado esses conteúdos no ensino médio, embora tenha alto interesse pelo assunto.

Questão 4: Qual o nível de importância que você dá para a sua formação (como futuro professor de Física) no que diz respeito a possuir conhecimentos sobre: TRR / TRG.

Tabela 4 - Respostas obtidas para a questão 4 do pré-teste

\begin{tabular}{|c|c|c|}
\hline Alternativas & TRR (\%) & TRG (\%) \\
\hline Nenhum & ---- & ---- \\
\hline Baixo & ---- & ---- \\
\hline Médio & 6,7 & 13,2 \\
\hline Alto & 93,2 & 86,7 \\
\hline
\end{tabular}

Fonte: dados de pesquisa

A mesma consideração realizada na terceira questão, pode ser feita sobre a questão 4, cujos dados estão dispostos na Tabela 4. Porém, nesse caso, a questão se refere aos conhecimentos adquiridos no curso de graduação, ou seja, a pergunta está relacionada ao fato de os estudantes serem potencialmente futuros professores. É evidente que se o estudante já houvesse estudado sobre esses assuntos na educação básica, os seus conhecimentos prévios provavelmente o auxiliariam para uma melhor compreensão quando ele fosse rever esses conteúdos no curso de graduação.

Questão 5: Você julga importante abordar no ensino médio conteúdos referentes à: TRR / TRG.

Tabela 5 - Respostas dadas para a questão 5 do pré-teste

\begin{tabular}{|c|c|c|}
\hline Alternativas & TRR (\%) & TRG (\%) \\
\hline Não & 0,0 & 0,0 \\
\hline Pouco & 33,2 & 53,2 \\
\hline Muito & 66,7 & 46,7 \\
\hline
\end{tabular}

Fonte: dados de pesquisa. 
Nesta questão, cujos resultados estão indicados na tabela 5, percebemos que as respostas se mostraram divididas, isto é, 66,7\% deles afirmaram julgar "muito importante" o ensino de TRR no ensino médio. Porém, no que diz respeito à TRG, a diferença foi menor entre "pouco" e "muito", ou seja, 53,2\% afirmaram julgar pouco importante abordar a TRG no ensino médio. O resultado dessa questão contrasta de forma pouco acentuada com o resultado das questões anteriores, em que a maioria respondeu ter interesse em estudar relatividade, entretanto, vai de encontro com a situação atual do ensino médio nacional, onde ainda não é unanime entre os professores, ou futuros professores, a convicção de que se deve trabalhar esses tópicos no ensino médio.

Os resultados obtidos com essas cinco questões possibilitam identificar o interesse dos acadêmicos no tema em discussão, cujos conhecimentos específicos foram analisados na sequência. Tais resultados são apresentados de modo a realizar um confronto entre o pré e o pós-teste. Para identificar a questão que assim como as anteriores tem sua numeração iniciando por "1", optamos por incluir ao lado que a questão se refere a "Conteúdos Específicos" representando pelas iniciais "CE"

Os resultados obtidos com essas cinco questões possibilitam identificar o interesse, sobre o tema em discussão, dos acadêmicos, cujos conhecimentos específicos (CE) foram analisados na sequência. Tais resultados são apresentados de modo a realizar um confronto entre o pré e pós-teste. Para identificação, as questões foram numeradas de 1 a 10 e acompanhadas das siglas CE.

Questão 1CE: Um corpo que efetua um movimento circular com velocidade angular constante em módulo pode ser considerado um referencial inercial?

Tabela 6 - Respostas obtidas na questão 1CE do pré-teste e do pós-teste

\begin{tabular}{|l|c|c|}
\hline Alternativas & Pré-teste (\%) & Pós-teste (\%) \\
\hline a) Sim & 6,7 & 18,7 \\
\hline b) Não & 86,7 & 81,2 \\
\hline Não respondeu & 6,7 & 0,0 \\
\hline \multicolumn{2}{|c|}{ Fonte: dados de pesquisa. } \\
\hline \multicolumn{2}{|c|}{} \\
\hline
\end{tabular}

O principal objetivo dessa questão, cujas respostas são apresentadas na tabela 6, estava em observar se os licenciandos apresentavam clareza sobre referenciais inerciais. Observa-se na tabela 6 que, praticamente o mesmo percentual de acadêmicos (variando de 86,7\% no pré-teste para $81,2 \%$ no pós-teste) respondeu a alternativa correta, tanto no pré-teste como no pós-teste, o que demonstra que não houve evolução significativa nas percepções dos estudantes. Isso pode ter ocorrido pelo fato de este ser um conhecimento referente à Física Clássica, algo que os alunos já haviam estudado anteriormente no próprio curso de graduação.

Questão 2CE: Segundo a teoria da relatividade restrita, as leis físicas para dois referenciais inerciais são: Alternativa "A" as mesmas; Alternativa "B" diferentes.

Tabela 7 - Respostas obtidas para a questão 2CE do pré-teste e do pós-teste

\begin{tabular}{|l|c|c|}
\hline \multicolumn{1}{|c|}{ Alternativas } & Pré-teste (\%) & Pós-teste (\%) \\
\hline a) As mesmas & 33,2 & 81,2 \\
\hline b) Diferentes & 13,2 & 18,7 \\
\hline Não respondeu & 53,2 & 0,0 \\
\hline
\end{tabular}

Fonte: dados de pesquisa. 
Os resultados mostrados na tabela 7 indicam uma evolução na percentagem da resposta correta (letra a), ou seja, de 33,2\% no pré-teste o índice passou para 81,2\% no pós-teste. Tal resultado pode estar relacionado ao fato de que, os alunos ainda não possuíam suficiente familiaridade com o princípio da relatividade galileana. Esse fato pode estar atrelado a constatação de que, mesmo que eles tenham trabalhado em outras disciplinas com conceitos referentes a cinemática, não é dada ênfase nesse princípio, visto que a sua formalização não é necessária para a resoluções da grande maioria dos problemas e exercícios presentes nos livros-texto de Física Geral.

Questão 3CE: Analise a situação a seguir: considerando que a velocidade da luz no vácuo tem um valor igual a c, suponha que você está viajando no vácuo dentro de uma nave muito veloz na mesma direção, porém em sentido contrário à de um feixe de luz. A velocidade da nave em relação à Terra é igual à metade da velocidade $c$, e a velocidade do feixe de luz em relação à Terra é igual a c. A velocidade do feixe de luz em relação à nave é igual a:

Tabela 8 - Respostas obtidas para a questão 3CE do pré-teste e do pós-teste.

\begin{tabular}{|l|c|c|}
\hline Alternativas & Pré-teste (\%) & Pós-teste (\%) \\
\hline a) $0,5 \mathrm{c}$ & 26,7 & 25,0 \\
\hline b) $1,5 \mathrm{c}$ & 40,0 & 18,7 \\
\hline c) c & 6,7 & 50,0 \\
\hline d) 2c & 6,7 & 6,2 \\
\hline Não respondeu & 20,0 & 6,2 \\
\hline \multicolumn{2}{|c|}{ Fonte: dados de pesquisa. } \\
\hline
\end{tabular}

Ao se observar as respostas para a questão 3CE (tabela 8), percebemos que no pré-teste 40,0\% dos acadêmicos responderam 1,5c, ou seja, a resposta que remete a uma concepção inerente à Física Clássica, e apenas cerca de 6,7\% responderam c, resposta que remete a uma concepção inerente à TRR. Contudo, no pós-teste, notamos que as respostas inerentes à Física Clássica diminuíram para 18,7\%, e as inerentes à TRR aumentaram para 50,0\%. Observando os resultados das questões 1CE e 2CE, Tabelas 6 e 7, respectivamente, percebe-se que, no que diz respeito aos postulados da TRR, houve um significativo aumento na porcentagem de respostas corretas dos alunos, o que mostra uma evolução no seu entendimento acerca dos conceitos.

Questão 4CE: Todos os observadores sempre concordarão sobre a simultaneidade de dois eventos?

Tabela 9 - Respostas obtidas para a questão 4CE do pré-teste e do pós-teste

\begin{tabular}{|l|c|c|}
\hline \multicolumn{1}{|c|}{ Alternativas } & Pré-teste (\%) & Pós-teste (\%) \\
\hline a) Sim & 6,7 & 0,0 \\
\hline b) Não & 93,2 & 93,7 \\
\hline Não respondeu & 0,0 & 6,2 \\
\hline
\end{tabular}

Fonte: dados de pesquisa.

Da tabela 9, constatamos que praticamente não houve mudanças nas respostas dos estudantes. Ou seja, tanto no pré-teste como no pós-teste, a maioria dos estudantes (mais de 93,0\%) respondeu a alternativa (correta) que remete à relatividade da simultaneidade oriunda da formulação da TRR. 
Questão 5EC: Qualquer observador no universo mediria o mesmo intervalo de tempo em relação a outro, desde que seus relógios estejam inicialmente sincronizados e em perfeitas condições de funcionamento?

Tabela 10 - Respostas obtidas para a questão 5CE do pré-teste e do pós-teste

\begin{tabular}{|l|c|c|}
\hline \multicolumn{1}{|c|}{ Alternativas } & Pré-teste (\%) & Pós-teste (\%) \\
\hline a) Sim & 6,7 & 0,0 \\
\hline b) Não & 80,0 & 100,0 \\
\hline Não respondeu & 13,2 & 0,0 \\
\hline \multicolumn{2}{|c|}{ Fonte: dados de pesquisa. } \\
\hline
\end{tabular}

Analisando os dados apresentados na tabela 10, notamos que houve evolução nas respostas dos estudantes após a aplicação da proposta didática, ou seja, as respostas que refletem a concepção relativística (letra b) cresceram de 80,0\% no préteste para 100,0\% no pós-teste. Essa evolução de 20,0\% deve ser levada em consideração para se verificar se houve mudança na compreensão do conceito por parte dos estudantes, porém, cabe destacar que, mesmo antes da aplicação da proposta, cerca de $80,0 \%$ dos estudantes já responderam a alternativa que remete à TRR.

Questão 6CE: Imagine que você vive em uma época em que as naves espaciais viajam a velocidades muito altas (próximas à da luz). Nesse caso, imagine uma pessoa dentro de uma nave que viaja a $80 \%$ da velocidade da luz em relação à Terra. Para essa pessoa, o tempo passaria?

Tabela 11 - Respostas obtidas para a questão 6CE do pré-teste e do pós-teste

\begin{tabular}{|c|c|c|}
\hline Alternativas & Pré-teste (\%) & Pós-teste (\%) \\
\hline $\begin{array}{l}\text { a) Mais rápido do que para outra pessoa em } \\
\text { repouso na superfície da Terra. }\end{array}$ & 6,7 & 0,0 \\
\hline $\begin{array}{l}\text { b) Da mesma forma que para outra pessoa em } \\
\text { repouso na superfície da Terra. }\end{array}$ & 13,2 & 0,0 \\
\hline $\begin{array}{l}\text { c) Mais devagar do que para outra pessoa em } \\
\text { repouso na superfície da Terra. }\end{array}$ & 80,0 & 100,0 \\
\hline
\end{tabular}

Fonte: dados de pesquisa.

Questão 7CE: Imagine dois irmãos gêmeos, ambos com 20 anos de idade. Um deles decide fazer uma viagem interplanetária. Ele parte e fica viajando durante 10 anos de acordo com o seu relógio. Considerando que a espaçonave permaneceu durante toda a viagem com uma velocidade constante de 99\% da velocidade da luz em relação à Terra, ao retornar à Terra, o gêmeo viajante percebe que?

Em ambas as questões, cujos resultados estão expressos nas tabelas 11 e 12 respectivamente, verificamos que parte dos estudantes responderam no pré-teste a alternativa que remete ao conceito relativístico (letra c), ou seja, 80,0\% para a 6CE e 73,2\% para a 7CE. Todavia, cabe ressaltar que, após a aplicação da proposta, no pós-teste, ainda houve uma evolução nessas respostas, ou seja, em ambas as questões, 100,0\% dos estudantes responderam a alternativa que remete ao conceito relativístico. 
Tabela 12 - Respostas obtidas para a questão 7CE do pré-teste e do pós-teste

\begin{tabular}{|c|c|c|}
\hline Alternativas & Pré-teste (\%) & Pós-teste (\%) \\
\hline $\begin{array}{l}\text { a) Seu irmão que permaneceu na Terra aparenta } \\
\text { estar mais jovem do que ele. }\end{array}$ & 13,2 & 0,0 \\
\hline $\begin{array}{l}\text { b) Não há nenhuma diferença de idade entre ele } \\
\text { e seu irmão que permaneceu na superfície da } \\
\text { Terra. }\end{array}$ & 13,2 & 0,0 \\
\hline $\begin{array}{l}\text { c) Seu irmão que permaneceu na Terra aparenta } \\
\text { estar mais velho do que ele. }\end{array}$ & 73,2 & 100,0 \\
\hline
\end{tabular}

Fonte: dados de pesquisa.

Questão 8CE: Imagine que um foguete passe próximo à Terra a uma velocidade muito próxima à da luz em relação ao planeta. Uma pessoa em repouso na superfície da Terra mede o comprimento do foguete. A medida realizada pelo observador terrestre será maior, menor ou igual a uma medida feita se o foguete estivesse em repouso na superfície da Terra?

Tabela 13 - Respostas obtidas para a questão 8CE do pré-teste e do pós-teste

\begin{tabular}{|l|c|c|}
\hline Alternativas & Pré-teste (\%) & Pós-teste (\%) \\
\hline a) Maior & 40,0 & 18,7 \\
\hline b) Menor & 33,2 & 62,5 \\
\hline c) Igual & 6,7 & 25,0 \\
\hline Não respondeu & 20,0 & 0,0 \\
\hline
\end{tabular}

Fonte: dados de pesquisa.

Na tabela 13, percebemos uma evidente evolução na concepção dos estudantes após a aplicação da proposta. As respostas não chegam a ser unanimes, mas o percentual que remete ao conceito formal relativístico quase dobra (de 33,2\% para 62,5\%).

Questão 9CE: Imagine que seja possível realizar o seguinte experimento: dois relógios (1 e 2) estão inicialmente sincronizados e em perfeitas condições de funcionamento. Em um segundo momento, eles são colocados, respectivamente, na superfície da Terra e nas proximidades de um buraco negro. Nesse caso, a medida de um intervalo de tempo será:

Tabela 14 - Respostas obtidas para a-questão 9CE do pré-teste e do pós-teste

\begin{tabular}{|l|c|c|}
\hline Alternativas & Pré-teste (\%) & Pós-teste (\%) \\
\hline $\begin{array}{l}\text { a) Maior nas proximidades do buraco negro e } \\
\text { menor na superfície da Terra. }\end{array}$ & 46,7 & 37,5 \\
\hline \begin{tabular}{l|l} 
b) Igual para os dois locais. \\
c) Menor nas proximidades do buraco negro e \\
maior na superfície da Terra.
\end{tabular} & 20,0 & 0,0 \\
\hline
\end{tabular}

Fonte: dados de pesquisa.

Observamos na tabela 14 uma evolução significativa nas respostas corretas (letra c) dos estudantes: de 33,2\% para 68,7\%. Outro aspecto que cabe ressaltar é que no pós-teste nenhum estudante respondeu que o tempo passa da mesma forma nos dois locais, ou seja, parece ter ficado claro que o tempo passa de formas diferentes dependendo dos locais. 
Questão 10CE: Sobre a trajetória de um feixe de luz ao passar nas proximidades de uma estrela, é correto afirmar que:

Tabela 15 - Respostas obtidas para a questão 10CE do pré-teste e do pós-teste

\begin{tabular}{l|c|c|}
\hline Alternativas & Pré-teste (\%) & Pós-teste (\%) \\
\hline \begin{tabular}{l|l} 
a) A trajetória segue em linha reta. \\
b) A trajetória é curvada no sentido da
\end{tabular} & 60,0 & 0,0 \\
\hline $\begin{array}{l}\text { estrela. } \\
\text { c) A trajetória é curvada no sentido contrário }\end{array}$ & 0,0 & 93,7 \\
$\begin{array}{l}\text { à estrela. } \\
\text { a }\end{array}$ & & 6,2 \\
\end{tabular}

Fonte: dados de pesquisa.

Para essa questão, percebemos pelo indicado na tabela 15, que no pré-teste as respostas ficaram entre as alternativas "a" e "b", com 40,0\% e 60,0\% para cada uma, respectivamente. Podemos inferir que os 40,0\% que responderam que a luz segue em linha reta talvez tenham se embasado no princípio de propagação retilínea da luz, porém, sem levar em consideração as possíveis curvaturas do espaço. No pós-teste, o valor percentual das respostas corretas aumentou para 93,7\%, salientando-se que nenhum estudante respondeu que a luz seguiria em linha reta.

Além das dez questões objetivas relativas ao conhecimento específico, o pré e pós-teste incluíam cinco questões abertas com respostas dissertativas que igualmente foram analisadas, buscando nos registros elementos que permitissem criar categorias com agrupamento de respostas. A partir dessa estruturação tais respostas foram organizadas na forma de tabelas e são analisadas na sequência. As questões que igualmente foram numeradas iniciando por "1", estão diferenciadas das anteriores pela inclusão da letra " $D$ ", correspondendo a "Dissertativa".

\section{Questão 1D: Caracterize um referencial inercial.}

Tabela 16 - Respostas obtidas na questão 1D do pré-teste e pós-teste

\begin{tabular}{|l|c|c|}
\hline Categorias & Pré-teste (\%) & Pós-teste (\%) \\
\hline $\begin{array}{l}\text { a) Está em repouso ou com velocidade } \\
\text { constante (sem aceleração) }\end{array}$ & 53,2 & 60,0 \\
\hline b) Possui inércia & 0,0 & 20,0 \\
\hline c) Se encontra em equilíbrio & 0,0 & 3,5 \\
\hline d) Está em repouso & 20,0 & 16,5 \\
\hline Não respondeu & 26,8 & 0,0 \\
\hline
\end{tabular}

Fonte: dados de pesquisa.

Os resultados mostrados na tabela 16, foram agrupadas na alternativa "a". Observamos que a maioria respondeu corretamente e houve uma sútil evolução do pré-teste para o pósteste (de 53,2\% para 60\%). Esse resultado demonstra que a maioria dos estudantes apresenta uma concepção correta de referencial inercial.

Questão 2D: O que significa dizer que dois eventos foram simultâneos? 
Tabela 17 - Respostas obtidas para a questão 2D pré-teste e pós-teste:

\begin{tabular}{|l|c|c|}
\hline Categorias & Pré-teste (\%) & Pós-teste (\%) \\
\hline a) Ocorreram no mesmo intervalo de tempo & 64,5 & 71,0 \\
\hline b) Ocorreram no mesmo instante & 24,5 & 11,1 \\
\hline c) Ocorreram no mesmo local & 11,0 & 0,0 \\
\hline d) Ocorreram no mesmo intervalo de tempo de & 0,0 & 17,9 \\
\hline acordo com um determinado referencial inercial & &
\end{tabular}

Fonte: dados de pesquisa.

As respostas indicadas na tabela 17 para questão 2D, que trata da concepção de simultaneidade sem ter a necessidade de fazer menção à TRR ou à TRG, tem como categoria correta a assinalada em " $b$ ". Analisando as respostas percebemos uma diferença entre os percentuais de "b" em relação a "a", o que pode estar relacionado à tênue distinção entre os conceitos de intervalo de tempo e instante, ou seja, um instante é um intervalo de tempo que tende a zero. Interpretamos esse resultado de forma positiva, pois a maioria dos alunos não diferenciou de forma significativa os conceitos de intervalo de tempo e instante, contudo, de certa forma, podemos considerar que as duas respostas estão corretas com as respectivas considerações. Todavia, cabe destacar que no pós-teste surgiram respostas que deram origem a uma nova categoria, a " $d$ ", onde os estudantes mencionam a necessidade de se adotar um referencial inercial, ou seja, a simultaneidade para eles precisa ser considerada relativa.

Questão 3D: Defina o conceito de tempo.

Tabela 18 - Respostas obtidas para a questão 3D pré-teste e pós-teste

\begin{tabular}{|l|c|c|}
\hline Categorias & Pré-teste (\%) & Pós-teste (\%) \\
\hline a) Medida da duração de eventos. & 6,7 & 16,6 \\
\hline b) Organização de tarefas do cotidiano. & 6,7 & 0,0 \\
\hline c) Quarta dimensão. & 13,2 & 16,6 \\
\hline d) Relacionado com a mudança. & 0,0 & 63,5 \\
\hline Não respondeu & 73,4 & 3,3 \\
\hline
\end{tabular}

Fonte: dados de pesquisa.

Na tabela 18, a categoria que corresponde a resposta esperada é a indicada pela letra "d", a qual não apareceu no pré-teste. Todavia no pré-teste, a maioria dos acadêmicos optaram por ela, apontando para o fato de que as atividades desenvolvidas possibilitaram construir argumentos favoráveis a essa resposta. Outro dado importante decorrente do indicado na tabela é que 73,4\% no pré-teste não responderam à questão; entretanto, no pósteste, apenas 3,3\% deixaram de respondê-la ou 16,6\% responderam de forma equivocada. Outro destaque é dado pela concepção filosófica dessa grandeza (algo que foi entusiasticamente discutido pelos estudantes durante uma das aulas), ou seja, para se definir um padrão de tempo, é necessário que haja alguma mudança de estado no sistema (categoria "d"). Essa é uma concepção que existe desde a Grécia antiga e perdura até os dias atuais, com as devidas considerações. No pós-teste, aproximadamente $63,5 \%$ dos estudantes relacionaram o conceito de tempo com algum tipo de mudança de estado no sistema.

No que diz respeito à maioria das categorias, pode-se observar uma diminuição no uso de falas que remetem a um conhecimento puramente de senso comum. Por exemplo, os 
acadêmicos responderam no pré-teste, respectivamente: "O tempo é uma forma encontrada para organizar eventos da nossa vida de uma forma mais simples"; "O tempo é o que determina a medida dos dias, horas, minutos e segundos". Já no pós-teste, os mesmos sujeitos responderam, respectivamente: "O tempo é uma forma de fazer uma contagem cronológica baseada em uma mudança que ocorre"; "Tempo é baseado em uma mudança de lugar ou estado. É qualquer mudança que respeite um padrão". Ambos relacionaram no pós-teste o tempo a uma mudança, todavia, também deixaram de relacionar essa grandeza apenas com eventos do cotidiano, dando-lhe um sentido mais amplo. Esse não foi do caso de outro estudante, que manteve basicamente a mesma resposta nos dois momentos: "Tempo é duração de fatos e períodos, determina momentos, horas, minutos, etc" (pré-teste); "O tempo é a duração dos fatos, é o que determina momentos" (pós-teste).

Questão 4D: Como se pode diferenciar um espaço plano de um espaço curvo?

Tabela 19 - Respostas obtidas para a questão 4D no pré-teste e no pós-teste

\begin{tabular}{|l|c|c|}
\hline \multicolumn{1}{|c|}{ Categorias } & Pré-teste (\%) & Pós-teste (\%) \\
\hline a) Pelo desvio na trajetória de um feixe de luz & 0,0 & 21,1 \\
\hline b) Por possuir deformações & 26,7 & 5,3 \\
\hline c) Pela validade das proposições da & 0,0 & 42,1 \\
\hline geometria euclidiana & & \\
\hline d) Medindo a sua curvatura & 6,7 & 0,0 \\
\hline e) Pela existência de aceleração & 6,7 & 10,5 \\
\hline f) Pela presença de massa & 13,2 & 10,5 \\
\hline Não respondeu & 46,7 & 10,5 \\
\hline
\end{tabular}

Fonte: dados de pesquisa.

A tabela 19 indica que, no pré-teste, as respostas dos acadêmicos denotavam, no geral, pouca formalidade científica, dado que se soma ao fato de aproximadamente $46,7 \%$ deles não responderam à questão. No pós-teste, foi possível observar uma notável evolução nas respostas, tendo que $42,1 \%$ dos sujeitos citou a questão da validade da geometria euclidiana. Tal aspecto foi amplamente debatido na proposta didática e pode ter repercutido nas respostas do pós-teste. Também, verificamos algumas respostas relacionadas ao fenômeno da deflexão da luz em um campo gravitacional, as quais foram agrupadas na categoria "a". Tais respostas podem estar vinculadas ao entendimento dos estudantes acerca de que o efeito da deflexão da luz é uma consequência de se assumir que o espaço é curvo, porém tal efeito também pode ser previsto pela Física newtoniana (a previsão feita pela Física Newtoniana corresponde a quase a metade do desvio que se observa, já a previsão da TRG corresponde ao observado com uma ótima aproximação), onde não se assume nenhuma curvatura para o espaço.

Questão 5D: Como é interpretado o fenômeno da gravitação segundo a teoria da relatividade geral de Einstein?

A tabela 20 ilustra que no pré-teste, a maioria dos acadêmicos (80,0\%) não responderam à questão, sendo ainda que as poucas respostas dadas estavam substancialmente relacionadas à gravitação universal de Newton. No pós-teste, houve uma evolução, porém, 38,5\% permaneceram sem responder. Em contrapartida, 30,7\% relacionaram o efeito gravitacional à curvatura do espaço. Um fato a ser destacado é que a categoria "b" pode ser 
entendida como uma resposta que está de acordo com a gravitação universal de Newton, assim como com a TRG de Einstein, tendo em vista que nos dois casos depende-se da massa dos corpos contida em uma determinada região do espaço.

Tabela 20 - Respostas obtidas para a questão 5D no pré-teste e no pós-teste

\begin{tabular}{|l|c|c|}
\hline Categorias & Pré-teste (\%) & Pós-teste (\%) \\
\hline $\begin{array}{l}\text { a) Concepção newtoniana (força que age a } \\
\text { distância). }\end{array}$ & 13,3 & 15,4 \\
\hline $\begin{array}{l}\text { b) Está diretamente relacionado com a massa } \\
\text { dos corpos. }\end{array}$ & 6,7 & 15,4 \\
\hline c) Pela curvatura do espaço. & 0,0 & 30,7 \\
\hline Não respondeu & 80,0 & 38,5 \\
\hline
\end{tabular}

Fonte: dados de pesquisa.

Elementos relacionados e essa questão foram discutidos nas atividades desenvolvidas no quarto e quinto encontro. Neles, os estudantes, apesar de interessados, apresentaram dificuldade no entendimento e aceitação acerca da ideia de o espaço-tempo possuir uma geometria curva. Essa dificuldade, aliada ao nível de abstração necessária para compreender tais ideias, pode ter influenciado na divergência das respostas a esta questão, tanto no pré, com no pós-teste.

\section{Diário de bordo}

O diário de bordo foi redigido pelo pesquisador ao final de cada encontro e ao assumir a condição de professor da turma. Nele foram transcritos momentos das atividades e inferências dos alunos. Por vezes, houve necessidade de anotações no transcorrer dos encontros, as quais subsidiaram a elaboração do texto no diário ao final do encontro. Com os registros feitos e constituintes dos dados coletados da pesquisa, procedemos à análise que, por sua vez, está descrita nesse trabalho. O objetivo está em oportunizar um melhor entendimento sobre as atividades realizadas em cada encontro, assim como a análise da atividade a partir de três aspectos: interação, dificuldade e aceitação.

O primeiro aspecto permeia o quanto as atividades propostas geraram interação, tanto entre os estudantes como entre eles e o professor e, possivelmente, com o material. 0 segundo aspecto direciona a uma reflexão acerca das dificuldades apresentadas pelos estudantes e observadas pelo pesquisador durante as aulas. $\bigcirc$ terceiro aspecto possibilita uma análise sobre a aceitação dos estudantes durante as aulas - desde a motivação inicial, quando é apresentada a proposta, até a satisfação em encerrar a atividade, atingindo ou não o objetivo traçado. A análise desses aspectos, juntamente com os resultados do pré-teste e do pós-teste, pode fornecer indícios sobre a potencialidade das atividades no âmbito educacional. As inferências extraídas do diário de bordo são destacadas em itálico, com correções de linguagem. Seguindo o apresentado no quadro 2, no primeiro encontro, apresentamos a proposta e aplicamos o questionário - pré-teste. Nos registros do diário, esse encontro foi marcado por momentos de empolgação por estudar os tópicos mencionados, mas também de angustia por se tratar de um tema considerado pelo grupo de difícil compreensão. No que diz respeito à interação, a apresentação da proposta gerou discussões entre os estudantes relacionadas ao nível de dificuldade do conteúdo e à vontade de aprender mais sobre o assunto. Todavia, podemos considerar que a aceitação do grupo foi bastante positiva. 
Em um segundo momento da aula, foram aplicadas duas atividades relacionadas à Física Clássica. O seguinte trecho extraído do diário de bordo faz menção a essas atividades:

Os estudantes receberam uma folha A4 com instruções para a realização da atividade e relataram as suas conclusões e considerações na própria folha que foi recolhida pelo pesquisador para uma posterior análise. As atividades promoveram discussões e argumentações por parte dos estudantes. Ao refletirem sobre os experimentos mentais propostos, os estudantes discutiam entre si [...] a discussão se mostrou produtiva, ao passo que os estudantes tentavam convencer e ajudar uns aos outros. Ficou evidente a adesão a uma postura colaborativa por parte dos integrantes.

Os dois experimentos mentais foram propostos para abordar, basicamente, o princípio da relatividade clássico. O principal objetivo foi estimular esse tipo de pensamento (imaginativo) junto aos estudantes, empregando-o para um conteúdo com o qual, supostamente, a maioria já tinha afinidade (Física Clássica). No que diz respeito à interação, as atividades promoveram discussões entre os estudantes e deles com o pesquisador, mas principalmente entre eles próprios, como relata o trecho do diário de bordo. A principal dificuldade observada foi no momento em que os estudantes tiveram que analisar o mesmo fenômeno com base em um referencial diferente, porém, isso serviu como elemento desafiador, auxiliando no processo de aprendizagem.

No segundo encontro, foram trabalhados os tópicos de relatividade da simultaneidade e dilatação temporal. Na sequência, temos um trecho extraído do diário de bordo:

\begin{abstract}
Inicialmente foi realizada pelo pesquisador uma explanação sobre caraterísticas da teoria eletromagnética de Maxwell. Na sequência foi efetuado o experimento da "surfagem no feixe de luz". Os estudantes se mostraram desafiados a resolver a questão, o que gerou bastante discussão entre os integrantes do grupo. Após algumas discussões históricas a respeito da origem da TRR, foram enunciados os dois postulados de Einstein. Para a relatividade da simultaneidade foi utilizado em um primeiro momento, uma atividade experimental de caráter introdutório antes de formalizar a questão para velocidades próximas à da luz. Para o desenvolvimento da atividade foram utilizadas ondas sonoras. Os estudantes se mostraram interessados em compreender a atividade experimental, o que gerou interação entre os mesmos e com o pesquisador. A atividade se mostrou bastante eficiente em termos de uma demonstração (mesmo que não relativística) de como a simultaneidade depende do estado de movimento do observador.
\end{abstract}

O trecho destaca dois aspectos importantes: o primeiro é a motivação observada nos estudantes quando são desafiados a resolver questões bastante abstratas e imaginativas; o segundo é o interesse por atividades experimentais concretas, onde se pode observar o fenômeno "acontecendo". Quanto à interação, notamos que o experimento mental proposto no início da aula promoveu de forma mais significativa a interação entre os estudantes, enquanto o experimento concreto (talvez por ser de caráter demonstrativo) promoveu mais a interação entre os estudantes e o pesquisador e entre os estudantes e o material. A princípio, não se observaram grandes dificuldades por parte dos estudantes no que diz respeito a essas duas atividades. Ambas foram bem aceitas, porém, cabe destacar que a expectativa para a 
atividade experimental concreta foi significativamente maior do que para o experimento mental.

Após essa atividade demonstrativa, de caráter introdutório, foi apresentado, em forma de narrativa pelo pesquisador o experimento do trem relativístico, que é frequentemente utilizado para se trabalhar esse conteúdo. Para a discussão desse experimento, foi projetada, em PowerPoint, uma sequência de imagens, a fim de demonstrar como se dá a relatividade da simultaneidade sob o ponto de vista relativístico para o caso do trem. Na continuidade, foi abordado a dilatação temporal, utilizando uma simulação computacional seguida da dedução da equação matemática. Percebemos que para esse tópico, a simulação computacional funcionou como um elemento facilitador no processo de aprendizagem, como evidenciado no registro do pesquisador:

A aula sobre dilatação temporal foi bastante expositiva até um determinado momento. Os estudantes se mostraram interessados quando foi apresentada a simulação computacional e acompanharam sem grandes dificuldades toda a dedução matemática da equação da dilatação temporal. Porém, a participação e discussão foram mais intensas ao final da explicação, quando levantadas as consequências da equação e exemplos como o do paradoxo dos gêmeos.

O fragmento do diário evidencia o quanto os participantes se mostraram desafiados por assuntos aparentemente contra intuitivos. Com efeito, a interação entre eles e deles com o pesquisador foi despertada no momento da discussão sobre a equação da dilatação temporal. Analisando esse dado sob o ponto de vista da interação, percebemos que a atividade foi mais significativa no momento das consequências e menos significativa durante a dedução da equação. A maior dificuldade observada nos alunos foi a de aceitar as consequências da equação da dilatação temporal, ou seja, alguns estudantes ficaram perplexos ao analisarem a equação e perceberem que, de fato, é possível que passe uma hora para um determinado observador enquanto passa um ano para outro. Todavia, essa dificuldade se mostrou como elemento motivador para esse grupo, revelando interesse em buscar mais informações sobre o assunto.

No terceiro encontro foi abordado o tema contração das distâncias, sendo utilizada inicialmente uma atividade prática de caráter introdutório para discutir o assunto, como mostra o diário de bordo do pesquisador:

A atividade prática de caráter introdutório foi realizada pelos estudantes com certo nível de facilidade e como foi efetuada em grupo promoveu uma significativa interação entre os estudantes de cada grupo. Quando foi feita a formalização para situações relativísticas surgiram algumas dúvidas, como, por exemplo, se o objeto de fato encolhe ou se trata de uma "ilusão". Sanadas essas dúvidas foram sugeridos alguns exercícios de fixação.

Podemos dividir essa parte da aula em dois momentos: no primeiro, os estudantes realizaram uma atividade prática de caráter introdutório; no segundo, foi realizada a formalização de maneira expositiva. No que diz respeito à interação aluno-aluno e alunomaterial, o primeiro momento se revelou mais frutífero, já que o segundo momento foi de pouca interação, por se tratar de uma parte da aula basicamente expositiva. Observamos certa dificuldade na compreensão formal e conceitual da contração das distâncias, ou seja, não se trata de uma ilusão decorrente do movimento dos corpos, ou de um simples 
"encolhimento" dos objetos. Dito de outro modo, o que ocorre sob o ponto de vista da TRR não é uma diminuição entre as distâncias moleculares, e sim uma consequência da relatividade da medida de espaço e tempo.

O trecho a seguir, extraído do diário de bordo, destaca elementos relacionados ao quarto encontro.

Para essa aula foram utilizadas, a princípio, duas metodologias distintas, ambas baseadas em experimentos mentais (o primeiro se trata de um experimento para discutir o princípio da equivalência, e o segundo, da relatividade do tempo no âmbito da TRG): uma se trata de um experimento mental em grupos de três a quatro estudantes, onde inicialmente cada estudante teve que realizar a atividade conduzido por um breve texto entregue para cada um. Após o término do proposto cada estudante deveria dividir as suas considerações com o grupo, promovendo uma discussão interna, que posteriormente seria levada para o grande grupo. Essa parte da aula gerou muita discussão tanto nos pequenos grupos como no grande grupo. A segunda metodologia foi realizar o experimento conduzido pelo professor, onde os estudantes foram aos poucos percebendo o que se propunha. Nesse segundo experimento foi mais evidente a interação entre os alunos e o professor, sendo que estes questionavam o mesmo durante a atividade.

O exposto destaca duas formas para contemplar experimentos mentais: conduzidos passo a passo pelo professor, podendo-se fazer indagações ao longo do desenvolvimento da experiência ou realizados de forma autônoma pelos estudantes. Ambas as possibilidades podem ser eficientes, cada qual com suas peculiaridades. Quando o estudante é protagonista, ele é estimulado a forjar toda a situação para tirar as conclusões. Já quando ele é conduzido pelo professor, perde um pouco a sua autonomia, todavia, para determinados assuntos, a eficiência do ponto de vista didático é maior. Ou seja, o professor pode estimular o estudante a perceber aspectos mais específicos inerentes ao objetivo da aula.

Tais metodologias geraram bastante interação, contudo, a primeira, em que os estudantes foram os protagonistas, mostrou-se mais eficiente. Em linhas gerais, não se observou muita dificuldade entre os estudantes durante as atividades, percebendo uma aceitação mais expressiva no momento em que os estudantes trabalharam de forma autônoma o experimento mental e discutiram nos grupos, observando-se envolvimento e entusiasmo.

No último encontro foram abordados conteúdos sobre espaço curvo e a deflexão da luz em um campo gravitacional. Do diário de bordo extraímos o seguinte trecho:

A atividade proposta para testar as proposições da geometria euclidiana a fim de definir espaços curvos foi bem aceita pela maioria, onde boa parte dos estudantes colaborou auxiliando uns aos outros nas medições, com exceção de alguns (poucos) que não se mostraram muito dispostos a realizar as medições, porém acabaram realizando a atividade. Observouse um pouco de dificuldade por parte de alguns estudantes no momento da visualização da curvatura do disco no experimento mental dos dois discos giratórios. A dificuldade foi esclarecida com a intervenção do pesquisador e com a ajuda dos colegas da turma. Sobre à atividade da cama elástica (utilizada tanto para fechar as discussões sobre espaço curvo, como para introduzir a deflexão da luz em um campo gravitacional) houve 
bastante interação principalmente entre os alunos e o pesquisador. 0 experimento da cama elástica se revelou uma boa alternativa para facilitador a compreensão desses conteúdos.

O fragmento do diário mostra que ambas as atividades promoveram uma interação entre os estudantes, principalmente na atividade em que, em grupo, eles precisaram fazer as medições nos espaços planos e curvos. Nessa atividade, todos se auxiliaram, adotando uma postura colaborativa que foi fundamental na construção do conhecimento pelos membros de cada grupo. Foi observada certa dificuldade por parte de alguns no momento de visualizar o experimento do disco giratório, a qual foi suficientemente sanada. Porém, fica evidente que em atividades que exigem um nível mais elevado de abstração e imaginação os estudantes ainda enfrentam maior dificuldade. Todas as propostas da aula foram acatadas pelos participantes, com exceção de um diminuto grupo que não aceitou a atividade de efetuar as medidas nos espaços planos e curvos. Todavia, é possível que isso tenha ocorrido por limitações pessoais, especialmente em atividades que envolvem medições ou qualquer atividade mais técnica.

\section{Considerações finais}

Tanto a TRR, como a TRG, tem a potencialidade de proporcionar uma visão mais ampla e diferenciada do mundo natural. Noções de tempo, espaço e matéria, drasticamente modificadas com a ascensão da FM, fazem parte do cerne de qualquer teoria física. A abordagem da TRR e da TRG no ensino médio, a exemplos de outros tópicos de FM, é amplamente recomendada pelas pesquisas na área de ensino de Física, conforme mencionado na introdução deste artigo. Porém, mesmo que se justifique a necessidade de abordar a FM no ensino médio, como especificado por Marques e Silva (2016) a sua inserção nesse nível de escolarização ainda enfrenta obstáculos. Dentre esses, destacamos à falta de material acessível ao professor e a necessidade de preparação dos mesmos desde seus cursos de formação inicial. Todas essas evidências remetem a uma outra necessidade que está associada à de se oferecer alternativas para que o professor de Física do ensino médio se sinta subsidiado ao trabalhar esses conteúdos. Tal identificação ancorou as investigações desenvolvidos neste estudo.

Em termos dos resultados, a investigação mostrou por meio da análise dos questionários, uma significativa evolução dos conhecimentos da maioria dos estudantes. Essa evolução ocorreu em relação a grande parte dos conceitos, todavia, em alguns não foi possível verificar a mesma evolução. Isso pode ter ocorrido porque, em alguns casos, os estudantes já possuíam um conceito formal estabelecido antes mesmo da aplicação da proposta e também porque, em outros casos, seria necessário mais tempo e maior aprofundamento para se construir o conceito de forma significativa.

Utilizando-se o diário de bordo como ferramenta de registro das aulas, foi possível evidenciar a aceitação dos estudantes no decorrer dos encontros. No geral, o assunto despertou significativamente o interesse da maioria dos estudantes. A utilização de diferentes ferramentas metodológicas, tais como experimentos mentais e de laboratório didático, vídeos, simulações, mostraram-se de extrema valia no processo de ensino-aprendizagem. A variabilidade na utilização de recursos metodológicos durante as aulas tem a potencialidade 
de estimular o interesse dos estudantes pelo assunto, motivando-os na realização das atividades (GIACOMELLI, 2016).

Por fim, mencionamos que o apresentado neste estudo não soluciona, nem tem a pretensão de solucionar o problema da ausência da FM no ensino médio. Contudo, pode ser uma alternativa para amenizá-lo e fomentar possibilidades de inserção desses conteúdos nessa etapa de escolarização. Sabemos que a melhoria na qualidade do ensino não depende de grandes revoluções, e sim de ações isoladas, que, ao serem somadas, promovem as mudanças desejadas na educação.

\section{Referências bibliográficos}

ASTOLFI, Jean Pierre; DEVELAY, M. A didática das ciências. Campinas: Papirus, 1995.

BALZA, Miguel A. Diários de aula: contributo para o estudo dos dilemas práticos dos professores. Porto: Porto Editora, 1994.

BRASIL. Ministério da Educação. Secretaria de Educação Média e Tecnológica. Parâmetros Curriculares Nacionais para o Ensino Médio. Brasília: Ministério da Educação/Secretaria de Educação Média e Tecnológica, 1999.

CHEVALLARD, Yves. La Transposición didáctica: del saber sabio al saber enseñado. Buenos Aires: Aique, 1991.

GIACOMELLI, Alisson C. Teoria da relatividade: uma proposta didática para o ensino médio. 2016. Dissertação (Mestrado em Ensino de Ciências e Matemática) - Universidade de Passo Fundo, Passo Fundo, 2016.

GIACOMELLI, Alisson C.; SAMUDIO PÉREZ, Carlos A. Compreendendo a teoria da relatividade: dos fundamentos às consequências. Produto educacional, Universidade de Passo Fundo, 2016. Disponível em: http://docs.upf.br/download/ppgecm/Alisson_Produto_Educacional.pdf. Acesso em 20 jun. 2017.

GONÇALVES, Kleber Ramos; BITTAR, Marilena. A distância entre o saber acadêmico e o saber ensinado revelado em um livro didático de matemática do $7^{\circ}$ ano: o caso da adição e subtração com números inteiros, Revista Amazônia, v. 13, n. 2, p. 107-123, 2017.

MARQUES, Adílio Jorge; SILVA, Claúdio Elias da. É possível uma iniciação científica no ensino médio como projeto para divulgação da Física Moderna e contemporânea? Revista Amazônia, v. 2, n. 9-13, 2016.

REZENDE JUNIOR, Mikael F. Fenômenos e a introdução de Física Moderna e Contemporânea no ensino médio. 2001. Dissertação (Mestrado em Educação) - Universidade Federal de Santa Catarina, Florianopólis, 2001.

ROSA, Cleci T. Werner da. A metacognição e as atividades experimentais no ensino de Física. 2011. Tese (Doutorado em Educação Científica e Tecnológica) - Universidade Federal de Santa Catarina, Florianópolis, Brasil, 2011.

TERRAZZAN, Eduardo A. A inserção da física moderna e contemporânea no ensino de Física na escola de $2^{\circ}$ grau. Caderno Catarinense de Ensino de Física, Florianópolis, v. 9, n. 3, p. 209214, dez. 1992.

TRIVIÑOS, Augusto N. S. Introdução à pesquisa em ciências sociais: a pesquisa qualitativa em educação. 4. ed. São Paulo: Atlas, 1994. 